\title{
DISCIPLINAS NA MODALIDADE A DISTÂNCIA NOS CURSOS DE GRADUAÇÃO PRESENCIAIS: FLEXIBILIZAÇÃO DA POLÍTICA E DESAFIOS DA SUA EXPANSÃO
}

RIO DE JANEIRO/RJ JUNHO/2018

\author{
LILIAN LYRA VILLELA - UCP - lyravillela@gmail.com \\ STELLA CECILIA DUARTE SEGENREICH - UFRJ - stella.segen@gmail.com
}

Tipo: Investigação Científica (IC)

Natureza: Relatório Final de Pesquisa

Categoria: Estratégias e Políticas

Setor Educacional: EDUCAÇÃO SUPERIOR

\begin{abstract}
RESUMO
O cenário político e a expansão da adoção de disciplinas semipresenciais por cursos de graduação na modalidade presencial são temas correlatos e tem caminhado lado a lado desde $2001 \mathrm{em}$ ritmos aparentemente opostos: grau de exigência decrescente no texto das portarias reguladoras e ritmo crescente de expansão na prática. Este trabalho tem como objetivo conhecer e explorar as mudanças tanto no teor da portaria atualmente vigente, 1.134/2016, quanto nos microdados dos censos do ensino superior publicados desde 2010 até 2016 pelo Instituto Nacional de Estudos e Pesquisas Educacionais Anísio Teixeira do Ministério da Educação. Assim, a revisão do texto político e a organização dos dados considerando as ocorrências específicas de cursos com oferta de disciplinas semipresenciais em relação à organização acadêmica, categoria administrativa, localização geográfica e área de conhecimento são capazes de tecer o mapa da realidade desafiadora ampliada pela aparente flexibilização e ausência de modelos apropriados para a correta inserção da educação a distância nos cursos presenciais. O resultado obtido revela que está em queda desde 2012 a quantidade de cursos presenciais sem oferta de disciplinas semipresenciais, enquanto que o total dos demais cursos que as oferecem em seu currículo dobrou no período, concentrando-se expressivamente na região sudeste e em instituições privadas. Paralelamente, a nova portaria manteve simplista sua orientação, sem traçar indicações quanto a: infraestrutura, formação docente, inserção no projeto pedagógico ou aspectos voltados à qualidade de experiência dos sujeitos envolvidos, notadamente alunos e professores. $O$ desafio de aperfeiçoar o processo de avaliação está posto.
\end{abstract}

Palavras-chave: Disciplinas Semipresenciais. Ensino Superior. Educação a Distância. Portaria 1.134/2016. 


\section{Introdução}

Este texto apresenta o relatório final de mais uma etapa da linha de investigação desenvolvida por pesquisadores dedicados ao estudo da educação a distância (EaD) no Brasil, no âmbito da Rede Universitas/BR. Cresce o número de pesquisas sobre os cursos de graduação a distância oferecidos tanto na rede pública, principalmente via Universidade Aberta do Brasil, como na rede privada em geral, mediante pesquisa bibliográfica, documental e estudos de caso. Este relatório não centra seu foco nos cursos a distância, avaliados (bem ou mal) nos processos de credenciamento específico exigidos com base nos marcos regulatórios relativos a esta modalidade de ensino. Esta pesquisa incidiu sua análise, entre 2006 e 2016, na porta aberta por duas portarias, baixadas em 2001 e 2004, que permitiram a introdução de disciplinas semipresenciais em até $20 \%$ do total da carga horária do currículo, gerando novas configurações acadêmicas que se tornaram objeto de estudo deste grupo como uma linha de investigação (SEGENREICH, 2006).

Até 2016 foram publicados vários textos em congressos e periódicos assim como defendidas dissertações e teses por integrantes do grupo sempre pautando a análise pela Portaria 4.059/2004, que ficou mais de dez anos em vigor. Tendo em vista que uma nova normatização relativa à incorporação de disciplinas online nos cursos presenciais de graduação foi produzida por meio da Portaria $n^{0} 1.134$ de 10/10/2016, retomamos a pesquisa bibliográfica e documental, neste texto, com o objetivo de detectar as mudanças introduzidas pela nova portaria e levantar dados estatísticos que permitam visualizar a realidade atual da expansão dessas disciplinas e os desafios que esta nova abertura legal pode gerar.

\section{2- Fundamentação Teórica}

Os estudos desenvolvidos e publicados no desenvolvimento desta pesquisa seguiram, principalmente, a abordagem do ciclo de políticas apresentada por Mainardes (2006), com base nas ideias de Stephen Ball e Richard Bowe. Estes dois autores distinguem três contextos primários do processo de formulação de uma política: influência, texto político e prática. Inicialmente foram analisadas as influências de organismos internacionais e grupos de poder presentes no ciclo de políticas. Em um segundo momento, a construção do texto político das portarias de 2001 e 2004 foi também objeto de vários estudos. Finalmente, a descrição das práticas ainda está sendo feita por meio de pesquisa bibliográfica em anais de congresso destacando-se vários estudos de caso tanto em instituições privadas como instituições públicas estaduais e federais. Como os ciclos de política têm uma dinâmica contínua de influência e construção do texto político, 
o novo decreto sobre inserção dessas disciplinas (BRASIL, 2016) nos fez retornar à fase de análise do texto político e das práticas que dele se derivarão.

\section{3- Procedimentos Metodológicos}

A pesquisa teve como objetos de estudo a nova legislação específica acerca de disciplinas semipresenciais em cursos de graduação presenciais e os microdados disponibilizados pelo Instituto Nacional de Estudos e Pesquisas Educacionais Anísio Teixeira (INEP) de censos da educação superior dos anos de 2010 a 2016, por serem dados oficiais do mesmo órgão que baixou a portaria aqui analisada. Propomos, portanto, uma análise documental a partir do levantamento de fontes, seguindo a definição de Quivy e Campenhout (2005, p.202) de que as mesmas podem ser "documentos manuscritos, impressos ou audiovisuais, oficiais ou privados, pessoais ou provenientes de um organismo, contendo colunas de números ou textos". Neste sentido, além do texto oficial das portarias em questão, também foram considerados como documentos os dados estatísticos dos censos de educação superior do INEP.

\section{4- Apresentação e Discussão dos Resultados}

\section{1- Comparando as Portarias Regulamentadoras de 2014 e 2016}

No Quadro 1 foram destacadas, em negrito, duas alterações significativas introduzidas no decreto de 2016 em relação a nomenclaturas adotadas para as disciplinas e para os docentes/tutores assim como mais facilidades de entrada para as instituições de ensino superior (IES).

Quadro 1 - Mudanças na Portaria 1.134/2006

\begin{tabular}{|c|c|}
\hline Portaria 4.059/2004 & Portaria 1.134/2016 \\
\hline $\begin{array}{l}\text { Art. } 1^{\circ} \text { As instituições de ensino superior do sistema } \\
\text { federal de ensino poderão introduzir, na } \\
\text { organização pedagógica e curricular de seus } \\
\text { cursos superiores reconhecidos. }\end{array}$ & $\begin{array}{l}\text { Art. } 1^{\circ} \text { As instituições de ensino superior que } \\
\text { possuam pelo menos um curso de graduação } \\
\text { reconhecido poderão introduzir, na organização } \\
\text { pedagógica e curricular de seus }\end{array}$ \\
\hline $\begin{array}{l}\text { a oferta de disciplinas integrantes do currículo que } \\
\text { utilizem modalidade semi-presencial, }\end{array}$ & $\begin{array}{l}\text { cursos de graduação presenciais regularmente } \\
\text { autorizados, a oferta de disciplinas na } \\
\text { modalidadea distância. }\end{array}$ \\
\hline \multicolumn{2}{|c|}{ Art. $2^{\circ}$.Parágrafo único. Para os fins desta portaria, entende-se que a tutoria das disciplinas ofertadas } \\
\hline $\begin{array}{l}\text { na modalidade semi-presencial implica na } \\
\text { existência de docentes qualificados em nivel } \\
\text { compativel ao previsto no projeto pedagógico do } \\
\text { curso, com carga horária específica para os } \\
\text { momentos presenciais e os momentos a } \\
\text { distância. }\end{array}$ & $\begin{array}{l}\text { na modalidade a distância implica na existência } \\
\text { de profissionais da educação com formação } \\
\text { na área do curso e qualificados em nível } \\
\text { compatível ao previsto no projeto pedagógico. }\end{array}$ \\
\hline
\end{tabular}


Fonte: BRASIL, 2004 e BRASIL, 2016.

A utilização da expressão "disciplina semipresencial" na portaria de 2004 permitiu que as IES inserissem estas disciplinas no currículo dos cursos presenciais, sem que fosse feita nenhuma exigência sobre a forma como as IES deveriam implementá-las. Sua substituição por modalidade a distância, segundo vários pesquisadores e consultores, faz esta portaria recair automaticamente na exigência de credenciamento específico até então contornado pelas portarias anteriores, mas explicitamente exigido pela Resolução CNE/CES 01/2016. Jacobs (2016, s/p) argumenta que, "Segundo esse parecer do Conselho Nacional de Educação, o EAD, como modalidade, caracteriza-se pelo "tripé metodologia, gestão e avaliação", sendo, por isso, mais amplo que a técnica usada", desta forma, ainda segundo o autor, "não basta uma modificação de projeto pedagógico para implantar o EAD".

Por outro lado, Silva, Maciel e Alonso (2017) destacam que nenhuma das três portarias fornece qualquer orientação adicional a respeito de suas exigências sobre os requisitos básicos que permitam avaliar qualitativamente a enunciada presença nos projetos pedagógicos incluindo métodos e práticas de ensino-aprendizagem que incorporem o uso integrado de tecnologias de informação e comunicação para a realização dos objetivos pedagógicos, bem como prever encontros presenciais e atividades de tutoria, com profissionais qualificados para esta função. O estudo de Gomes e Catapan (2017, p.1) sobre o acoplamento presencial - virtual nas IES brasileiras converge nesta crítica de que esta última regulamentação abre mais portas, mas "não estabelece critérios e processos de avaliação para o acompanhamento das IES e verificação da qualidade dos projetos".

O caput do segundo artigo permanece inalterado em relação à versão anterior, porém seu parágrafo único apresenta mudanças substanciais: a indicação clara de que os profissionais da educação (anteriormente denominados docentes) devem possuir formação na área do curso e, por outro lado, a remoção total da referência à necessidade de carga horária específica para momentos presenciais e a distância. $O$ fato do tutor passar a ser denominado de profissional da educação também tem gerado polêmica na medida em que, na prática institucional, ele desempenha muitas vezes 0 papel docente, com resultados bastante positivos.

Finalmente, observa-se uma formulação regulatória simplista no terceiro artigo quando se restringe à simples comunicação da alteração do projeto pedagógico de cursos que passam a contemplar disciplinas online, postergando sua avaliação aos episódios de reconhecimento de cursos ou sua renovação. O estudo de Silva, Maciel e Alonso (2017, 
p.97) levanta a questão hipotética de que tal ausência de detalhamento possa ter "ocasionado diferentes interpretações" e, com isso, dificultado a implantação do ensino híbrido, presencial e virtual, nas universidades federais. A conclusão da pesquisa realizada em 2016 confirma tal hipótese, ao revelar que apenas 14,3\% das instituições federais regulamentaram a oferta de disciplinas online em seus cursos superiores. Dentre as questões levantadas para o estágio atual de adoção dessas disciplinas figuram as lacunas na regulamentação atual, tais como: falta de informações sobre 0 processo de atualização do projeto pedagógico, infraestrutura tecnológica necessária para a implantação e a capacitação docente para o uso das tecnologias da informação e comunicação (SILVA, MACIEL, ALONSO, 2017).

\section{2- Analisando os Microdados do Censo da Educação do INEP}

Os registros obtidos para a análise dos microdados do INEP foram organizados considerando apenas a tabela sobre cursos de cada ano do censo, de 2010 até 2016. Seguindo os filtros recomendados pelo INEP, a pesquisa é delimitada aos cursos de graduação e à identificação das ocorrências em que existe oferta de disciplinas na modalidade a distância ou semipresenciais (segundo o INEP) nos cursos presenciais. Para tanto, é utilizada a variável "IN_OFERECE_DISC_SEMI_PRES" do tipo "Sim" ou "Não" (anteriormente denominada "IN_OFERECE_DISC_DISTANCIA").

A Tabela 1, com o crescimento acumulado ano a ano ilustra a evolução da oferta de disciplinas semipresenciais, que em 2016 atinge 11.542 cursos, superando o dobro do total de 5.587 cursos em 2010 (107\% de variação).

Tabela 1: Crescimento da Oferta Acumulada - 2010 a 2016

\begin{tabular}{l|r|r|r|r|r|r|r|r}
\hline Cursos & $\mathbf{2 0 1 0}$ & $\mathbf{2 0 1 1}$ & $\mathbf{2 0 1 2}$ & $\mathbf{2 0 1 3}$ & $\mathbf{2 0 1 4}$ & $\mathbf{2 0 1 5}$ & $\mathbf{2 0 1 6}$ & $\begin{array}{l}\text { Variação } \\
\mathbf{2 0 1 0 - 2 0 1 6}\end{array}$ \\
Presenciais & 28577 & 29376 & 30718 & 30791 & 31513 & 32028 & 32665 & $14 \%$ \\
\hline Com oferta semipresencial & 5587 & 6177 & 6724 & 7542 & 9027 & 9990 & 11542 & $107 \%$ \\
\hline Sem oferta semipresencal & 22990 & 23199 & 23994 & 23249 & 22486 & 22038 & 21123 & $-8 \%$ \\
\hline A Distância & 930 & 1044 & 1148 & 1258 & 1364 & 1473 & 1662 & $79 \%$ \\
\hline Total de Cursos & 29507 & 30420 & 31866 & 32049 & 32877 & 33501 & 34327 & $16 \%$ \\
\hline
\end{tabular}

Fonte: INEP, 2017.

Os números indicam que 35\% do total de cursos presenciais (11.542 em relação ao total de 32.665) oferece disciplinas semipresenciais e que esta oferta está crescendo. Como é possível observar na Tabela 1 acima, o número de cursos presenciais sem disciplinas 
semipresenciais vem caindo desde 2013. A taxa negativa de variação de 2010 a 2016 do total de cursos sem oferta de disciplina semipresencial (-8\%) reforça a hipótese sobre a tendência de que a maioria dos cursos presenciais passem a oferecer alguma disciplina a distância.

A progressão entre as duas ocorrências é apresentada no Gráfico 1.

Gráfico 1: Oferta de Disciplinas Semipresenciais em Cursos - 2010 a 2016

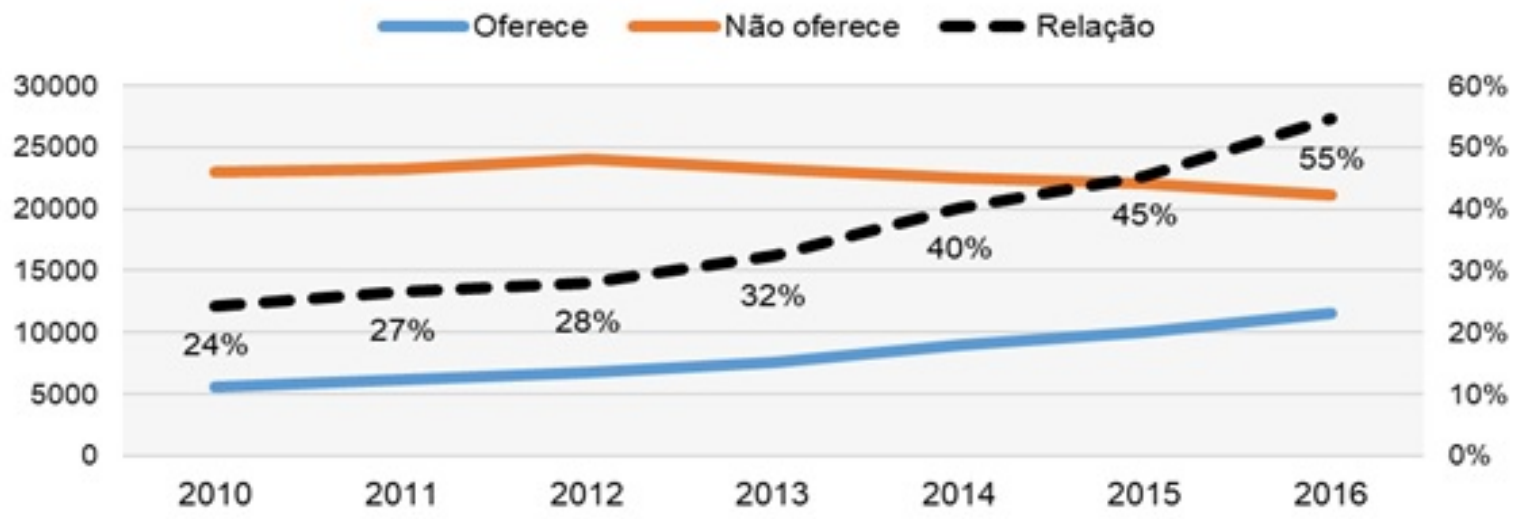

Fonte: INEP, 2017

A linha tracejada no gráfico da oferta de disciplinas semipresenciais representa a relação entre o total anual de cursos com oferta em relação aos sem oferta de disciplina semipresencial e ilustra o progressivo aumento de cursos dos primeiros em relação aos demais, em declínio a partir de 2013.

A busca por respostas a partir dos microdados filtrados segundo a variável indicativa de oferta de disciplina semipresencial apresenta novas luzes também para a compreensão da natureza e localização das IES envolvidas.

Os microdados do INEP permitem identificar a categoria administrativa, organização acadêmica e localização geográfica, dados que, organizados a seguir em relação ao universo de interesse, podem favorecer a compreensão dos caminhos de expansão da oferta de disciplinas semipresenciais.

Tabela 2: Cursos por Categoria Administrativa - 2010 a 2016 


\begin{tabular}{l|r|r|r|r|r|r|r|r|r}
\hline & $\mathbf{2 0 1 0}$ & $\mathbf{2 0 1 1}$ & $\mathbf{2 0 1 2}$ & $\mathbf{2 0 1 3}$ & $\mathbf{2 0 1 4}$ & $\mathbf{2 0 1 5}$ & $\mathbf{2 0 1 6}$ & $\mathbf{\%} \mathbf{2 0 1 6}$ & $\mathbf{2 0 1 0 / 2 0 1 6}$ \\
\hline Privada sem fins lucrativos & 3570 & 3790 & 3762 & 4121 & 4762 & 5004 & 5738 & $50 \%$ & $161 \%$ \\
\hline Privada com fins lucrativos & 1853 & 2007 & 2396 & 2904 & 3741 & 4476 & 5190 & $45 \%$ & $280 \%$ \\
\hline Pública Estadual & 7 & 9 & 23 & 15 & 74 & 230 & 311 & $3 \%$ & $4443 \%$ \\
\hline Pública Federal & 111 & 193 & 265 & 178 & 231 & 200 & 210 & $2 \%$ & $189 \%$ \\
\hline Especial & 0 & 0 & 250 & 294 & 204 & 53 & 56 & $0 \%$ & $0 \%$ \\
\hline Pública Municipal & 46 & 178 & 28 & 30 & 15 & 27 & 37 & $0 \%$ & $80 \%$ \\
\hline Total Geral & $\mathbf{5 5 8 7}$ & 6177 & $\mathbf{6 7 2 4}$ & $\mathbf{7 5 4 2}$ & $\mathbf{9 0 2 7}$ & $\mathbf{9 9 9 0}$ & $\mathbf{1 1 5 4 2}$ & $\mathbf{1 0 0 \%}$ & $\mathbf{2 0 7 \%}$ \\
\hline
\end{tabular}

Fonte: INEP, 2017.

A principal conclusão obtida a partir da Tabela 2 de cursos por categoria administrativa é que as instituições privadas detêm $95 \%$ do universo total de cursos presenciais com oferta de disciplinas semipresenciais. Também é possível observar o aumento expressivo recente da sua adoção entre as organizações públicas estaduais, subindo de poucos casos nos primeiros anos, para 311 em 2016.

Tabela 3: Cursos por Organização Acadêmica - 2010 a 2016

\begin{tabular}{l|rr|r|r|r|r|r|r|r}
\hline & $\mathbf{2 0 1 0}$ & $\mathbf{2 0 1 1}$ & $\mathbf{2 0 1 2}$ & $\mathbf{2 0 1 3}$ & $\mathbf{2 0 1 4}$ & $\mathbf{2 0 1 5}$ & $\mathbf{2 0 1 6}$ & $\mathbf{\%} \mathbf{2 0 1 6}$ & $\mathbf{2 0 1 0 / 2 0 1 6}$ \\
\hline Universidade & 3479 & 3619 & 3898 & 3977 & 4378 & 4745 & 4898 & $42 \%$ & $141 \%$ \\
\hline Faculdade & 1333 & 1584 & 1834 & 2393 & 3031 & 3374 & 4113 & $36 \%$ & $309 \%$ \\
\hline Centro Universitário & 772 & 965 & 974 & 1145 & 1579 & 1826 & 2469 & $21 \%$ & $320 \%$ \\
\hline $\begin{array}{l}\text { Institutos e Centros } \\
\text { Fed. de Educação }\end{array}$ & & & & & & & & & \\
Tecnológica & 3 & 9 & 18 & 27 & 39 & 45 & 62 & $1 \%$ & $2067 \%$ \\
\hline Total Geral & $\mathbf{5 5 8 7}$ & $\mathbf{6 1 7 7}$ & $\mathbf{6 7 2 4}$ & $\mathbf{7 5 4 2}$ & $\mathbf{9 0 2 7}$ & $\mathbf{9 9 9 0}$ & $\mathbf{1 1 5 4 2}$ & $\mathbf{1 0 0 \%}$ & $\mathbf{2 0 7 \%}$ \\
\hline
\end{tabular}

Fonte: INEP, 2017.

A Tabela 3 torna visível, além da crescente adoção dos $20 \%$, que faculdades estão se aproximando cada vez mais do espaço percentualmente ocupado pelas universidades. Os centros universitários aumentam ano após ano sua participação nesta fatia e os institutos federais de educação, ciência e tecnologia, somados aos centros federais de educação tecnológica progridem na adesão oferta semipresencial.

O cruzamento entre categorias administrativas mais expressivas por organização acadêmica evidencia as faculdades, dentre as privadas com fins lucrativos (2.633 cursos em 2016) e as universidades, dentre aquelas sem fins lucrativos (2.979 cursos em 2016), numa variação, respectivamente de 372\% e 124\% entre os anos de 2010 e 2016. 
Quanto à localização geográfica dos cursos com oferta de disciplinas semipresenciais em 2016, ela pode ser visualizada no Gráfico 2.

Gráfico 2: Dispersão Geográfica de Cursos com Oferta de Disciplinas Semipresenciais 2016

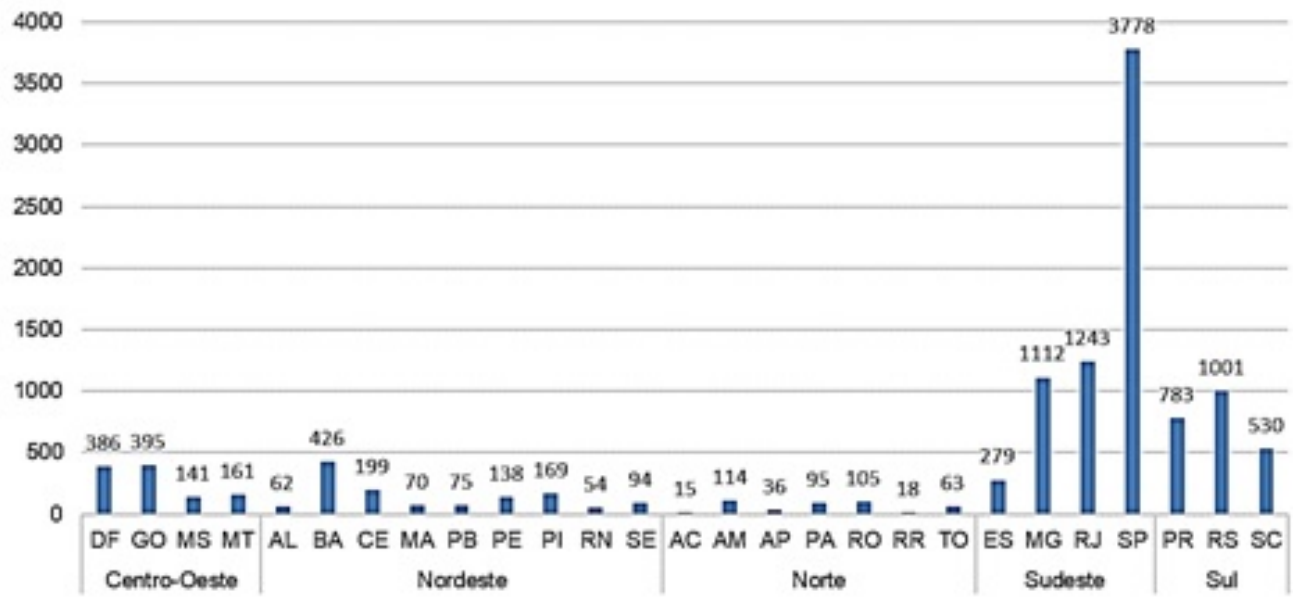

Fonte: INEP, 2017.

É claramente visível a concentração dos cursos de graduação que oferecem disciplinas online na região sudeste, 6.412 casos ou $56 \%$ do total, notadamente no estado de São Paulo ( 3.778 ou $59 \%$ do total da região ou $33 \%$ do total geral). A região norte ocupa 0 extremo inferior das ocorrências, 446 casos ou $4 \%$ do total.

Finalmente, a distribuição por área geral de conhecimento em 2016 indica que a maioria ou $37 \%$ dos cursos com oferta de disciplinas semipresenciais encontra-se na área geral de Ciências Sociais, Negócios e Direito (4.254), seguida das áreas de Educação (1.720), Saúde e Bem Estar Social (1.641) e Engenharia, Produção e Construção (1.605), cada uma com cerca de $15 \%$ das ocorrências. As áreas com menor incidência de disciplinas a distância no último censo são: Agricultura e Veterinária (168), Serviços (423), Humanidades e Artes (521) e Ciências, Matemática e Computação (1.210 ou 10\% do total geral).

Este panorama indica que a região sudeste e os cursos da área de Gerenciamento e Administração (2.100), Formação de Professor de Matérias Específicas (880), Contabilidade e Tributação (539), Terapia e Reabilitação (496), Direito (488), Marketing e Publicidade (480) fazem parte do contingente de adesão expressiva e crescente ao modelo semipresencial, sem, contudo, alguma indicação de crescimento de informação quanto à sua efetividade ou qualidade como experiência educativa. 


\section{Conclusões e Recomendações}

Passados 12 anos de investigação retomamos as seguintes questões levantadas por Segenreich em 2006:

O que o MEC tinha em mente quando abriu esta possibilidade em 2001 e a ratificou em 2004, sem incluí-la na nova regulamentação da Educação a Distância, aprovada em dezembro de 2005? [...] Que modelos de oferta de disciplinas semi-presenciais vem sendo adotados? Que modelos são válidos e como devem ser avaliados? (p.14)

A resposta à primeira questão tem sido objeto de discussão na comunidade acadêmica e há um consenso no sentido de detectar uma política de aceleração da expansão da rede privada no caminho da $\mathrm{EaD}$ e a atuação de atores influentes nestas portarias.

Quanto aos modelos de oferta e avaliação de sua qualidade, houve omissão do MEC em explicitar o que entendia por educação a distância. Somente em 2016 é feita uma análise mais aprofundada pelo Conselho Nacional de Educação e uma definição, citada por Jacobs, mas ainda não operacionalizada. Os instrumentos de avaliação do INEP ao unificar a avaliação das modalidades presencial e a distância para autorização e reconhecimento dos cursos, após a extinção da Secretaria de Educação a Distância tirou a possibilidade dos avaliadores perceberem os modelos de inserção da EaD nos cursos presenciais. A revisão dos instrumentos de avaliação torna-se necessária assim como o desenvolvimento de estudos de caso que desvelem os diferentes tipos de modelo adotados na experiência prática das instituições públicas e privadas, na medida em que não faltam novas nomenclaturas mal exploradas tais como aula invertida, acoplamento, blended learning, hibridização.

\section{Referências Bibliográficas}

BRASIL. Ministério da Educação (MEC). Portaria 4059 de 10 de dezembro de 2004.D.O.U.de 13 de dezembro de 2004, seção 1, p.34. Disponível em http://portal.mec.gov.br/sesu/arquivos/pdf/nova/acs_portaria4059.pdf . [Acesso em 12/05/18]

MEC.Portaria 1.134 de 10 de outubro de 2016. Revoga a Portaria MEC $n^{\circ}$ 4.059, de 10 de dezembro de 2004, e estabelece nova redação para o tema. Disponível em: https://abmes.org.br/legislacoes /detalhe/1988/portaria-n-1134. [Acesso em 12/05/18]

GOMES, Kelly Aparecida; CATAPAN, Araci Hack. Políticas públicas de regulação de "20\% a distância": acoplamento presencial-virtual nas IES Brasileiras. In: Congresso 
Internacional de Educação a Distância - CIAED, 2017, Foz do Iguaçu, PR. Anais (online). São Paulo: ABED, 2017. Disponível em http://www.abed.org.br/congresso2017.pdf. [Acesso em:07/05/18].

INEP, Instituto Nacional de Estudos e Pesquisas Educacionais Anísio Teixeira. Microdados Censo da Educação Superior. Atualizado até 2017. Disponível em:> http://portal.inep.gov.br/web/guest/microdados [Acesso em 12/05/18].

JACOBS, Edgar. A Portaria 1.134/2016, o método não presencial e os cursos híbridos. Revista Gestão Universitária. 14/10/2016. Disponível em:http://www.gestaouniversitari a.com.br/artigos/a-portaria-1-134-2016-o-metodo-nao-presencial-e-os-cursos-hibridos [Acesso em 14/04/18].

MAINARDES, Jefferson. Abordagem do ciclo de políticas: uma contribuição para a análise de políticas educacionais. Revista Educação e Sociedade. Campinas, v. 27, n. 94, p. 47-69, jan./abr. 2006.

QUIVY, R.; CAMPENHOUDT, L. Manual de Investigação em Ciências Sociais. Lisboa: Gradiva, 2005.

SEGENREICH, Stella C. D. Desafios da Educação a Distância ao Sistema de Educação Superior: a invasão silenciosa dos "vinte por cento". X Seminário Estadual da ANPAE. São Paulo, 28 a 30 de junho de 2006. IN: Anais. Disponível em http://www.anpae.org.br/ [Acesso em 18/11/14].

SILVA, Michelle R. C.; MACIEL, Cristiano; ALONSO, Kátia M. Hibridização do ensino nos cursos de graduação presenciais das universidades federais: uma análise da regulamentação. Revista Brasileira de Política e Administração da Educação (RBPAE) - v. 33, n. 1, p. 95 - 117, jan./abr. 2017. Disponível em http://seer.ufrgs.br/index.php/rbpae/article/view/74042/41701 [Acesso em 12/05/18] 